\title{
ALGUNAS CONSIDERACIONES SOBRE LOS SERVICIOS MUNICIPALES DE CARACTER ECONOMICO
}

\section{Sectores de la competencia municipal.}

Es bien conocido que la esfera de la competencia municipal puede fundamentalmente dividirse en tres sectores. Es el primero el relativo a la constitución del Municipio y a aquellas actividades encaminadas a conservarse y subsistir, y comprende las normas orgánicas, constituciones, cartas, ordenanzas, estatutos de funcionarios, así como las elecciones, nombramientos, aposentamientos, etc. Pero después de esa actividad, semejante a la que el organismo humano necesita para su mera subsistencia, aquella otra que se propone un fin fuera del ente municipal se divide, a su vez, en dos campos: el del gubernativo, fundamentalmente político, y el de lo económicoadministrativo. Nuestras leyes suelen referirse desde antiguo a estas dos esferas de la actividad local, con las denominaciones de: gobierno y administración, precisando dentro de ésta última lo que suele denominar competencia económica administrativa. Análogamente, los autores alemanes separan la Administración de autoridad (Hoheitsverwaltung) de la Administración de empresa (Betreibsverwaltung).

\section{Creciente predominio de la económica.}

Desde hace aproximadamente medio siglo, la proporción respectiva de una y otra de estas dos esferas de competencia viene alterándose en detrimento de la primera y en aumento de la segunda. En el Municipio del siglo XIX, lo que atraía la atención de legisladores y tratadistas, lo que daba realce a la función municipal era precisamente la parte política y gubernativa. Censos, elecciones, orden 
público, policía y buen gobierno, etc. En cambio, la actividad económica tenía mucha menos importancia.

Nunca, sin embargo, se redujo ésta tanto, con referencia al antiguo régimen, como en la esfera de la administración del Estado. Jamás llegó a aplicarse en el Municipio la doctrina liberal del "laisser faire, laisser passer", con la misma intensidad con que se aplicó en el orden nacional. Es que el Municipio, por su propia naturaleza, tiene un carácter tan predominante de comunidad económica, que no se concibe que pueda, ni siquiera en teoría, reducirse a la emanación de normas y vigilancia de su cumplimiento por los particulares. De todas suertes, las leyes, el ambiente, la limitación de medios, el bajo nivel de vida de las masas populares y otra porción de factores eran adversos al desarrollo de los servicios municipales de contenido económico.

En nuestros días ha ocurrido lo contrario. No solamente el $\mathrm{Mu}$ nicipio ha ido recobrando aquellas facultades que tuvo en tiempos anteriores, con las variantes que las circunstancias exigen, sino que el campo de su actividad se ha ampliado a sectores completamente nuevos. Simultáneamente que de los fines pasamos a la manera de cumplirlos, la administración municipal ha ido tendiendo a preferir aquellos modos de ejecución de los servicios que exigen la organización de medios personales y materiales directamente dependientes a estrechamente relacionados con el propio Municipio.

\section{Modos de satisfacer las necesidades públicas.}

He hecho notar muchas veces que la Administración puede fundamentalmente valerse de cuatro modos o maneras para conseguir una finalidad cualquiera 0 , más concretamente, para satisfacer una necesiciad pública. Es el primero el procedimiento de la policía, dando a esta palabra el sentido amplio que suele recibir en los estudios administrativos, es decir, el de limitación de la libertad de los súbditos: la Administración no hace nada por sí, salvo establecer reglas de obligatorio cumplimiento que prohiben o condicionan la realización de actos perjudiciales para el fir que se trata de lograr. El segundo sistema, puramente jurídico, consiste en la emanación de normas $u$ órdenes que obligan a los particulares a realizar actos encaminados al fin que se trata de lograr. El tercer medio está expresado de modo insuperable con una palabra muy castellana y difícilmente sustituíble: la del fomento; la Administración, cuando se vale de él, estimula por los más variados procedimientos a personas y en334 tidades para que satisfagan la necesidad de que se trata, utilizando 
premios, subvenciones, estímulos honoríficos o, simplemente, la propaganda, la educación, etc. Finalmente, la Administración puede satisfacer la necesidad pública a que nos referimos mediante una actividad especial, bien ejercida mediante sus propios órganos, bien valiéndose indirectamente de entes que la sustituyen y obran en su nombre.

$S_{1}$ queremos ver prácticamente en un ejemplo cómo obran estos cuatro procedimientos, podemos fijarnos en una de las más típicas y constantes necesidades de la vida urbana: la limpieza y ornato de la vía pública. Respecto de ellas, el Municipio puede limitarse a prohibir a los vecinos y transeúntes: el depósito y lanzamiento al arroyo de basuras, papeles y demás objetos, así como todo uso que pueda ensuciar o afear las calles: es el sistema de la policía. Puede obligar, mediante ordenanzas y bandos, a que los vecinos y comerciantes procedan a barrer, regar y iimpiar la parte de vía pública que linde con sus fronteras o fachadas; y éste será el segundo de los procedimientos indicados. Cabe que establezca premios, estímulos y diplomas u otras ventajas para aquellos vecinos o asociaciones de ellos que mejor cuiden y conserven sus respectivas calles; y así se valdrá del fomento. Finalmente, creado el servicio de limpiezas, puede llevarlo a cabo directamente por su propia organización o bien concederlo, arrendarlo o encomendarle de otro modo a quienes actúen en su nombre y bajo su fiscalización.

Puede formularse como una constante de nuestra evolución administrativa en los últimos ciento cincuenta años el paso sucesivo para cada una de las necesidades de la población de uno a otro de esos cuatro sistemas, por el orden en que los he enumerado. Cada vez son más raros los bandos; y el habitante de cualquiera de nuestras grandes ciudades pasa, por lo común, su vida entera sin tener jamás entre sus manos un ejemplar de las ordenanzas municipales. En cambio, los servicios municipales de contenido económico, que tropezaban hasta recientemente con un recelo general, cada vez disfrutan de mayor favor y van siendo considerados como el modo normal y de mayor eficacia para satisfacer una necesidad general.

Si nos fijamos en la enumeración de fines considerados como propios de la competencia municipal que suelen contener nuestras leyes, advertiremos que el mayor número de los que allí se mencionan con. siste en el manejo de bienes o en la regulación de actos que tienen un claro contenido económico. 


\section{Capacidad de los Ayuntamientos en el orden económico.}

Todo ello plantea, de una parte, el problema de la capacidad de los Ayuntamiento para estas actividades económicas. De otra, la ardua cuestión de cuáles sean las normas de ejecución que mejor convengan para la realización de esos fines.

No me he propuesto tratar en estas páginas de la primera de esas cuestiones, sobre la que en otros lugares he escrito con mayor extensión. De las dos doctrinas que desde antiguo se combaten y disputan el predominio en este punto: la de la especialidad y la que pudiéramos llamar de la Sociedad total, considero más exacta y conveniente la última.

Sabido es que, según la doctrina de la especialidad, son los Ayuntamientos entidades creadas o reconocidas por el Estado para fines determinados y que, por consiguiente, sólo son capaces y pueden disfrutar de personalidad para aquellos actos que la ley expresamente les autorice. En cambio, según el punto de vista que comparto, los Municipios, tanto si han nacido espontánea y naturalmente como si - cual frecuentemente ocurre-han sido creados por una acción reflexiva del Estado, pertenecen al grupo de sociedades que desde los escolásticos se denominan totales. En consecuencia, es punto menos que imposible enumerar todas las finalidades $\mathrm{y}$ actividades que un Municipio puede lícitamente cumplir. De ahí que sea preferible reconocer que, de la misma manera que nadie ha pensado hacer en el Código civil una enumeración de los fines permitidos a una persona natural y de las actividades lícitas para cumplirlas, tampoco en el orden del régimen local cabe proceder de esa manera, siendo preferible el otorgamiento y la capacidad plena para todo lo que sea beneficioso para la comunidad local, es decir, para cuanto convenga al interés del común de vecinos.

Dentro de este campo inmenso de la actividad económica de los Municipios, quiero destacar algunos aspectos que estimo merecedores en el momento actual de una atención especial.

\section{El Manicipio considerado como consumidor.}

Uno de los más interesantes es el concerniente a ese conjunto de actos en que el Municipio se presenta no sólo como productor, sino como un consumidor excepcional. Se trata de un tema casi inédito entre nosotros, no obstante su extraordinaria importancia, que ha determinado en otros países muchos estudios e investigaciones 
y que se ha concretado en potentes organismos que desarrollan una actividad beneficiosa y creciente.

Lns Ayuntamientos españoles consumen hoy cantidades ingentes de los más diversos productos: unas veces primeras materias, otras, productos manufacturados. $\mathrm{Y}$ este consumo se realiza del modo más anárquico, como en los tiempos primitivos, de manera que, a los que conocemos un poco la vida municipal, unas veces nos causa risa y otras enfado.

Una encuesta sobre el modo cómo los Ayuntamientos rurales y aún los de poblaciones de cierta categoría adquieren los mecanismos y material preciso para sus servicios de incendios, riego, limpiezas, casas de socorro, oficinas, parques y jardines, etc., nos convencería de que en la mayor parte de los casos las Corporaciones proceden como podría hacerlo el más incauto e inexperto muchacho. Incluso los Ayuntamientos de muchas ciudades importantes carecen de un servicio de compras en que se hagan estudios de los tipos más ventajosos, se procure saber cuáles son los resultados obtenidos en otros paises y en otras poblaciones del nuestro y se les compare con los propios; en que se lleve un fichero de costes comparados y, en suma, en que se procure utilizar la experiencia propia y la ajena para lograr el mayor rendimiento con la menor expensa.

En muchos países extranjeros esta situación se ha superado. Los grandes Municipios poseen todos ellos servicios especiales de compras y suministros, capacitados para informar en cada caso sobre el tipo deseable de cada clase, materia, objeto o mecanismo que haya de adquirirse, así como para estudiar comparativamente los resurtados.

En cuanto a los pequeños Municipios, se benefician de organizaciones especiales, comúnmente llamadas "Centrales de compras y suministros". Muy varios son los tipos de esta clase de entidades, pero en todas ellas se dan características comunes, persiguiéndose la obtención de ventajas que, según el Comisario de Compras de la ciudad de Nueva York, Russell Forbes, en su libro "Purchasing for Small Cities", son las siguientes:

1. Centralización de las facultades para realizar las compras.

2. Utilización de personal especializado y competente.

3. Fijación de normas y estipulaciones que garantizan la calidad de las mercancías.

4. Centralización de las necesidades, para hacer pedidos grandes que permiten obtener precios reducidos.

5. Estímulo de la libre concurrencia entre los proveedores. 
6. Examen y comprobación de la calidad de las mercancías suministradas.

Cabe añadir que la experiencia así obtenida y el personal técnico formado por los Servicios y Centrales de Compras son de la más grande utilidad para la política de abastos, que ha vuelto en nuestros días a tener una importancia semejante a la que alcanzó en períodos varias veces seculares de la historia de la Administración.

\section{Viviendas y edificios públicos.}

Otro orden de actividades económicas municipales de máxima actualidad entre nosotros es el que se refiere a la construcción de viviendas y de edificios destinados a albergar los servicios locales. Atravesamos en España un momento gravísimo. Es difícil que se haya encontrado el país en una situación semejante a la en que se halla hoy, desde este punto de vista. La falta de viviendas es un fenómeno que se da con intensidad a veces mayor en las pequeñas poblaciones que en las grandes ciudades, habiendo adquirido en éstas caracteres agudísimos. Al mismo tiempo, las destrucciones sufridas durante la guerra, la paralización de las obras de este ca:ácter durante aquel período y el ritmo menor en que las dificultades actuales mantienen la construcción, han impedido hacer frente a las nuevas necesidades dimanantes del desarrollo de los servicios anteriores. y la creación de muchos otros nuevos.

El sistema de estímulo, no obstante la perfección que ha alcanzado en las últimas leyes, no basta. Las Corporaciones locales, además de colaborar con el Estado asesorando y difundiendo las ventajas ofrecidas por éste, tendrán que intervenir de modo más directo, llegando a la constitución de empresas mixtas que realicen rápidamente las construcciones requeridas.

Importantísimo es en este terreno el que, siempre que se trate de llevar a cabo reformas urbanas, sobre todo de carácter interior, se tenga muy presente que es más importante y necesario que las familias que constituyen la población de un Municipio vivan en hogares decorosos, que el dotar a la ciudad de grandes vías y plazas espectaculares. De ningún modo debería permitirse el derribo de un barrio, con el necesario desahucio de sus habitantes, sin que previamente se hubieran construído las casas precisas para albergarlos, de modo, cuando menos, igual, desde el punto de vista higiénico y económico, al que antes lo estaban. 